\title{
LA CORPORLIDAD COMO NUEVOS TERRITORIOS DE
} ESPACIALIDAD RELIGIOSA

\section{- CRISTINA TERESA CARBALLO}

RESUMEN: EXISTE BASTANTE REVISIÓN TEÓRICA COMO EMPÍRICA SOBRE LA NOCIÓN TERRITORIO, CUERPO Y LA ESPACIALIDAD RELIGIOSA. El PRINCIPAL APORTE DE ESTE TRABAJO, PROBABLEMENTE, SEA ESTABLECER VINCULACIONES Y NEXOS ENTRE ELLOS PARA PODER INTERPRETAR LAS CONTEMPORÁNEAS FORMAS DE CORPORALIDAD ENTENDIDA, Y EXTENDIDAS EN SUS DIVERSAS MANIFESTACIONES. CUERPOS QUE EXPRESAN CARTOGRAFÍAS COMO FORMAS DE RELIGIOSIDAD. EL ARTíCULO SE ORGANIZA DE LA SIGUIENTE MANERA: UNA PRIMERA FASE PLANTEA ALGUNAS IDEAS SOBRE CUERPO Y TERRITORIO DESDE SU CONCEPCIÓN SOCIAL Y CULTURAL. UN SEGUNDO EJE ES TOMAR EL CUERPO COMO TERRITORIO SAGRADO. A LA VEZ, PRESENTA PERSPECTIVAS QUE VAN DESDE LA GLOBALIZACIÓN Y SUS EFECTOS EN LA CONSTRUCCIÓN DE LA IDENTIDAD, A LOS MOVIMIENTOS INDÍGENAS QUE PLANTEAN RESISTENCIAS Y PERTENECÍA CULTURAL REIVINDICATORIA DE SUS FORMAS SOCIALES Y VALORIZACIONES. UN TERCER Y ÚLTIMO MOMENTO, PRETENDE REPLANTEAR AL CUERPO Y AL TERRITORIO COMO EXPRESIONES Y APROPIACIONES DE LA REALIDAD RELIGIOSA CONTEMPORÁNEA.

PALABRAS CLAVE: TERRITORIO, CUERPO, RELIGIOSIDAD, CORPORALIDAD.

El propósito de este artículo es provocar el debate y algunas reflexiones en el campo geográfico entorno a un tema que nos atraviesa en lo cotidiano, como lo es el trinomio creencias, cuerpo y territorio. Estos conceptos han tenido en sus significados, en sus raíces teóricas y empíricas, influencias de las ciencias naturales en el marco del auge del positivismo que repercutió en todo el campo científico cuyos contenidos básicos se fueron completando a lo largo de un proceso histórico durante el siglo XIX y XX. Este proceso legitimó no solo la cosmovisión occidental en su lectura de la realidad social sino que también influyó en las formas de apropiación espacial de los recursos, el territorio y las personas. Esta visión histórica ha sido reformulada por otros enfoques 
innovadores a lo largo del siglo XX, en especial a partir de la década de los años '70. En este contexto, el saber geográfico ha dado un giro socrático y ha retomado, como actualizado, algunos supuestos que hacen al quehacer de la Geografía Cultural, renovada y crítica. Existe bastante revisión teórica como empírica sobre la noción territorio, cuerpo y la espacialidad religiosa. Probablemente el principal aporte de este trabajo sea establecer vinculaciones y nexos entre ellos para poder interpretar las contemporáneas formas de corporalidad entendida, y extendidas en sus diversas manifestaciones. Cuerpos que expresan cartografías como formas de religiosidad. En este sentido se asume al cuerpo como el territorio inmediato. Las visiones contemporáneas en las ciencias sociales se cuestionan el control del cuerpo, el control del territorio y el alcance de la esfera pública de lo religioso. En el caso latinoamericano la modernización incompleta culminó el proceso iniciado hace más de 5 siglos en lo que hace a deslegitimar y desplazar las cosmovisiones de los pueblos originarios y los significados complejos del territorio, cuerpo y creencias religiosas. Cada vez más, el mundo globalizado es cuestionado por sus sociedades. Aparecen emergentes sociales de espacialidad religiosa, por un lado, asociado con la movilidad territorial de la población que conlleva cambios en las formas sociales de organizar el espacio local y una circularidad de creencias y bienes religiosos en diversas latitudes sociales. Por el otro lado, la reivindicación cultural del territorio de los pueblos originarios en Latinoamérica ha permitido rescatar cosmovisiones con una carga de significados más complejos de la noción cuerpo, territorio y religión.

La espacialidad corporal y sus marcaciones territoriales está presente en todas las expresiones religiosas contemporáneas o tradicionales, en los rituales, en las peregrinaciones, en los sacrificios, en los tatuajes y símbolos, en los homenajes y festejos, en las danzas, en los transes, entre otras manifestaciones. De esta manera, el cuerpo adquiere una relevancia hasta ahora poco visible para el análisis geográfico de lo religioso. Análisis para nada sencillo, dado que no solo se refiere a la espacialidad entendida como herramienta para la comprensión social de la organización territorial de las prácticas religiosas, simbolismos, territorialidades, migraciones, nomadismo como diversificación de la oferta religiosa, circularidad de bienes de salvación, reconstrucción folclórica y turismo religioso, memoria e identidad, lugares sagrados e hierofanías, Estado-religión y nacionalismos, por nombrar algunas perspectivas recientes de la geografía cultural. Objetos que se abordan en diversas escalas, en una dinámica donde aparecen desregulaciones no solo de la hegemonía religiosa, sino en la organización social, y esto conlleva a nuevos escenarios inciertos, en los que el territorio conocido es el cuerpo: referente central en la individualización, sin mediación institucional de experiencias con lo divino.

Antes de continuar se explicita que los aportes invaluables de Le Breton (1992) sobre la sociología del cuerpo permitieron sistematizar una serie de cuestionamientos frente al dominio del 
cuerpo y su fragmentación. Sin dejar de lado a Foucault que introduce ácidamente la cuestión del poder y el control social, y por supuesto a Bourdieu que permite analizar la dinámica y estructura del poder desde los campos sociales partiendo del habitus y del capital cultural (entre otros aportes) para poder complejizar el análisis del espacio social. Desde nuestra óptica enriquece también el análisis espacial de las sociedades. Por otro lado, la disciplina geográfica y la geografía cultural no han sido indiferentes a estas revisiones sociales del conocimiento. La intención no es detenernos en estos aportes sino partir de ellos para poder avanzar en la interpretación que nos provocan estas nuevas cartografías que hacen de su cuerpo un medio territorial de expresión de la religiosidad contemporánea, una prolongación del cuerpo, un referente de identidad territorial, entre tantas otras formas de visualización social.

El presente trabajo surgió en el Núcleo de Estudos e Pesquisas sobre Espaço e Cultura de la UERJ, el que organizó el II Simpósio Nacional e Internacional sobre Geografia e Religião. En esa ocasión se presentaron las primeras ideas e imágenes sobre el cuerpo como territorio religioso, proponiendo una revisión más del territorio y del cuerpo al plantearla como una dimensión espacial más de la expresión religiosa. El artículo retoma algunos de los ejes presentados, el que se organiza de la siguiente manera: una primera fase plantea algunas ideas sobre cuerpo y territorio desde su concepción social y cultural. Un segundo eje es tomar el cuerpo como territorio sagrado. A la vez, presenta perspectivas que van desde la globalización y sus efectos en la construcción de la identidad, a los movimientos indígenas que plantean resistencias y pertenecía cultural reivindicatoria de sus formas sociales y valorizaciones. Un tercer y último momento, pretende replantear al cuerpo y al territorio como expresiones y apropiaciones de la realidad religiosa contemporánea.

\section{El cuerpo como territorio: aproximaciones culturales y sociales}

¿Qué permanece y que cambió en el análisis espacial frente a los territorios y cuerpos? A modo de aproximación podríamos avanzar en algunos aspectos teóricos sobre estos términos y sus resignificados en las ciencias sociales. En relación al territorio, la realidad nos abruma sobre el significado político, un tramo signado por el recrudecimiento de las tensiones sociales y fundamentalmente, por el creciente protagonismo de los movimientos sociales en búsqueda de su identidad y legitimación frente al Estado y/o frente al mercado. Muchas veces es el cuerpo el mediador y símbolo del reclamo social. Sobre estas expresiones tenemos para elegir: los cuerpos desnudos de los campesinos al ingresar a la región metropolitana de México D.F., los abrazos a los edificios históricos, los cuerpos en ayuno, entre otros. En estos casos, la percepción que se tiene del territorio de pertenencia y de expresión colectiva, no condice con la visión de quienes ven en él solo una fuente de recursos, o un bien que se cotiza en el mercado. En este escenario, las acciones colectivas resignifican al territorio no tan solo como un espacio físico. Y esto tiene 
consecuencias porque estamos asistiendo también a un momento de profundos cuestionamientos del pensamiento que legitima el orden desigual impuesto en América. El cuerpo de conceptos que lo sostenían, comienza a desdibujarse generando cierta incertidumbre teórica. Ya no queda claro de qué realidad da cuenta, por ejemplo, un concepto como el de territorio. Giménez (2001, p. 5), antropólogo, nos presenta una ajustada síntesis a partir de su interés en definir el concepto de territorio. Para ello, abrevará en aguas de la Geografía Cultural renovada rompiendo con las visiones estadocentristas y fijas de la noción territorio. Su síntesis nos viene a cuenta dado que es impecable su reconstrucción. "Se entiende por territorio el espacio apropiado y valorizado por un grupo social para asegurar su reproducción y la satisfacción de sus necesidades vitales. Se trata de un concepto multiescalar que puede ser aprehendido en diferentes niveles de la escala geográfica. Los geógrafos han elaborado también el concepto de paisaje en estrecha relación con el de territorio, ya que se considera al primero como símbolo metonímico y componente diferenciador de este último. La cultura, entendida como pauta de significados, constituye una dimensión fundamental del territorio, porque la apropiación del espacio no tiene sólo un carácter instrumental sino también simbólico-expresivo. Así entendido, el territorio constituye el marco obligado de ciertos fenómenos sociales, como el arraigo, el apego y el sentimiento de pertenencia socioterritorial, por un lado, y la movilidad, la migración y hasta la globalización, por otro".
El territorio, concepto complejo, lo profundiza recientemente Benedetti (2011) que resalta los procesos epistemológicos y políticos que asume esta noción, aunque quizás el meollo de la cuestión lo plantee Lobato Correa (1995) cuando se refiere al concepto de espacio, y sus dos corrientes igualmente -confundidas y- difundidas que sustentan al territorio y sus acepciones. Es decir el espacio absoluto y el espacio social. Y de allí las referencias teóricas del territorio.

El camino recorrido frente a la noción territorio ha sido vasta, y a pesar de las diferenciaciones epistémicas e históricas existen quizás convergencias en el hecho de que sus significados conviven más allá del abordaje que se haga del espacio, como también conviven con sus significados entre las funciones políticas y las académicas. El territorio, finalmente, es una herramienta -tanto teórica como empírica- para la comprensión de la realidad social y cultural, como es para el abordaje corporal desde la dimensión religiosa en tiempos contemporáneos.

En el mismo sentido que la noción territorio, la evolución y rupturas del significado de la noción del cuerpo han hecho un profuso camino teórico, y cabe retomar las raíces de la revisión de Le Breton (2002). El cuerpo en las ciencias sociales redimensiona el estudio de la corporeidad humana como fenómeno social y cultural, materia simbólica, objeto de representaciones y de imaginarios. Todas las acciones sociales implican necesariamente cierta corporeidad. A través del cuerpo se establecen significaciones precisas del mundo que rodea al sujeto social. El hombre como tal en el terreno 
físico se origina en un conjunto de sistemas simbólicos. "Del cuerpo nacen y se propagan las significaciones que constituyen la base de la existencia individual y colectiva" (...) "el cuerpo produce sentido continuamente y de este modo el hombre se inserta activamente en un espacio social y cultural dado" (LE BRETON, 2002, p.7-8)

Las representaciones del cuerpo son una función de las representaciones de la persona. Las representaciones de la persona y las del cuerpo, corolario de aquéllas, están siempre insertas en las visiones del mundo de las diferentes comunidades humanas. El cuerpo está construido socialmente. La designación del cuerpo traduce un hecho del imaginario social. Entre sociedades, la caracterización del hombre con su cuerpo y la definición de los constituyentes de la carne del individuo son datos culturales no estáticos. La identificación del cuerpo como fragmento de algún modo autónomo del hombre presupone una distinción no aceptada por muchas sociedades. En las sociedades tradicionales con un fuerte componente comunitario, la persona se subordina al colectivo. "A la inversa, en las sociedades individualistas, el cuerpo es el interruptor, marca los límites de la persona, es decir, donde comienza y termina la presencia de un individuo." (...) "El cuerpo no existe en el estado natural, siempre está inserto en la trama del sentido, inclusive en sus manifestaciones aparentes de rebelión, cuando se establece provisoriamente una ruptura en la transparencia de la relación física con el mundo del actor." (LE BRETON, 2002, p. 32-33) Esta diferenciación entre culturas del cuerpo no es un tema menor ni superficial, dado que en la expresión de la dimensión espacial de la religiosidad adquirirán materialidades y representaciones distantes aunque el nexo sea el cuerpo o la corporalidad del gesto o la apariencia. La expresión de lo religioso se simboliza en el cuerpo pero en una trama cultural cambiante y diversa. En este sentido, se seleccionan algunas visiones del cuerpo que abordan la mirada indígena para hacer énfasis no en el caso sino en la estructura y práctica del cuerpo frente a la experiencia religiosa. En estos casos la naturaleza tiene un papel central.

La re interpretación en la etnografía del cuerpo en las culturas amerindias permite una mirada ahora legitimada por el corpus científico y el político en materia territorial. Por ejemplo: "Encontramos frecuentemente en la etnografía amazónica la creencia generalizada de que el hecho de tener un cuerpo de homo sapiens no es garantía para constituir un 'humano'. En otras palabras, el cuerpo de un humano no es un objeto 'natural'; el cuerpo del humano deber ser construido activamente por medio de la alimentación, las curaciones, las marcas y transformaciones. Si desde un punto de vista no-indígena entendiéramos que lo que existe es una única naturaleza humana, común a todos, sobre la cual se construyen múltiples 'culturas' humanas; en una perspectiva contrastante habríamos de entender que tenemos una única cultura (la humana) sobre la cual se construyen múltiples naturalezas humanas. En lugar de un multiculturalismo, como afirma Viveiros de Castro, hablaríamos más bien de un multinaturalismo." (ECHEVERRI, 2004, p. 272) Este autor ha estudiado comunidades amazónicas y 
las relaciones con el Estado en la legitimación del territorio y los recursos. Con ello las concepciones de naturaleza y cuerpo aparecen atravesadas. Por el otro lado, el Estado con una visión más simplista y geométrica del territorio y no por ello, ingenua. "Las palabras, como 'territorio', pueden ser las mismas pero representar asuntos enteramente distintos. No es tanto que tengan 'significados' diferentes, sino que, al estar ubicadas en perspectivas diferentes, no tienen manera de hacer referencia a los mismos objetos. En el ejercicio político que hemos revisado [el caso del manejo territorial del Parque Cahuinarí], el asunto central de la negociación no deriva del problema de las diferentes concepciones culturales que habría necesidad de poner en 'diálogo', sino más bien el problema de establecer buenas relaciones sociales que permitan el crecimiento y la reproducción del cuerpo" (2004, p. 274), cuando se refiere a este cuerpo, es en sentido de un todo, naturaleza, territorio y sociedad. La especialización del territorio genera un tejido relacional con los territorios de otros. Una característica de la noción territorial es su forma de red y su estructuración a partir de los canales (apropiación de energía o sustancia vital de otro territorio). La cosmovisión indígena nos amplía la relación entre creencias y el cuerpo como manifestación territorial, en un sentido de integración cultural con el medio.

En nuestras sociedades urbanas observamos casos diversos de la corporalidad de lo religioso, dado que el cuerpo es expresión de sentimientos y experiencias. Los sentimientos que experimentamos repercuten y se expresan físicamente en nosotros. Están arraigados en normas colectivas implícitas. Estos sentimientos adquieren muchas veces materialidad territorial a partir del cuerpo. En definitiva, la marca social y cultural del cuerpo puede llevarse a cabo a través de una escritura directa de lo colectivo sobre la carne del actor.

El cuerpo fue disciplinado desde la historia de las civilizaciones y hoy adquiere una dimensión diferente frente al protagonismo que representa en las sociedades. Así de esta forma, el cuerpo humano reproduce en pequeña escala los poderes que se atribuyen a la estructura social.

¿El cuerpo como cartografía social? El cuerpo como unidad individual e indivisible del sujeto, territorio que se apropia como una forma de expresión. El cuerpo metaforiza lo social, y lo social metaforiza al cuerpo. En el recinto del cuerpo se despliegan simbólicamente desafíos sociales y culturales. Para finalizar, en palabras de Le Breton "Después de un largo período de discreción, el cuerpo hoy se impone como un lugar predilecto del discurso social. El cuerpo es el lugar defensor del individuo, su socio. La pérdida de la carne del mundo obliga al actor a apegarse a su cuerpo para darle carne a su existencia. El cuerpo se convierte en el alter ego del que emanan sanaciones y seducción" (2002, p. 91) Y podríamos agregar, el cuerpo se hace territorio, en el sentido social de su construcción y validación colectiva.

También el gesto, la postura o el movimiento corporal se comprenden desde las prácticas sociales. Una de ellas es la vía analógica. Las personas colonizan nuevos espacios gestuales trasladando matrices de gestos de unos ámbitos de 
su vida cotidiana a otros. El objetivo de inicial del Marcel Mauss (1934) en su obra clásica Les Techniques $d u$ corps fue analizar los gestos corporales desde una posición que cuestiona el por qué de su práctica. La naturaleza del gesto o del movimiento se planteó como interrogantes y han enriquecido la interpretación del cuerpo como producto social. "Es decir no puso mayor interés por el acto creador de las técnicas corporales, que consideraba del dominio de la psicología. Solo así es posible reconocer la huella de lo social sobre el cuerpo. Sin embargo la impronta de lo social no es la impronta de lo racional. Mauss no se refiere a la técnica como la acción de la razón sino más bien como la acción de la sociedad sobre el cuerpo. La visión del gesto y del movimiento que tenía Marcel Mauss era socio-mágica desde la perspectiva del origen del gesto, e inconsciente desde la perspectiva del gesticulador. Las personas, o bien porque quieren romper con una analogía gestual previa, o porque estiman que un nuevo acopio gestual es necesario, o porque necesitan rentabilizar el gesto, la postura o el movimiento para conseguir un resultado concreto, generan un nuevo encadenamiento de gestos. Un racionalismo diferente al racionalismo mitológico de Mauss, sin principio ni fin, aunque reconoce el hecho creador, lo disuelve en la sociedad, creando una sociedad sin cuerpo o, si se quiere, una sociedad en donde la razón del gesto se oculta". (DE LA CALLE VALVERDE, 2011, p. 80)

No hay duda de que el cuerpo y el gesto son moldeados por el contexto social y cultural en el que se sumerge el actor. El cuerpo es el nexo directo y privilegiado de la relación con el mundo.
Comprende las actividades perceptivas, pero también las expresiones de los sentimientos, los ritos de interacción, de belleza, la puesta en escena de la apariencia, las técnicas y diferenciaciones corporales, el sufrimiento y el dolor, la memoria y la identidad de un terruño lejano, o la relación con lo espiritual y el bienestar. El cuerpo territorio sagrado o profano desde la dimensión religiosa, es un lugar más, es un locus social como cultural.

Para cerrar esta parte del análisis resulta necesario retomar algunas ideas de Bourdieu respecto al campo religioso, que si bien fue novedoso, hoy resulta casi en un antecedente histórico cuando observamos las intensas transformaciones sociales frente a lo religioso y su espacialidad tanto en la escala latinoamericana como mundial. En este sentido, Bourdieu planteaba que por la propia posición de las instituciones religiosas en la estructura de la distribución del capital religioso, éstas dirigen todas sus estrategias hacia la lucha por el monopolio del ejercicio legítimo del poder religioso. Poder que se ejerce sobre los laicos y que acompaña por ende a la gestión de los bienes de salud, en la medida en que consigue imponer el reconocimiento de su monopolio (extra ecclesiam nulla salus, fuera de la iglesia no hay salvación). Y así tiende a perpetuarse, a prohibir más o menos completamente la entrada al mercado de nuevas empresas de bienestar tales como las sectas o todas las formas de comunidad religiosa independientes. Ahora esto genera una discusión en torno a la gestión del capital religioso (lo sagrado) y el cuerpo. El cuerpo siempre fue fuente de ejercicio de poder y control en las religiones. En el caso de 
las iglesias tradicionales el manejo del cuerpo y las relaciones sociales no son simétricas sino que se complementan, en un mundo social fragmentado y escindido; aunque las instituciones si se organicen y actúen a modo de cuerpo. El cuerpo es una marca material de lo social: su corporalidad y su imagen generan diferencias, límites y fronteras a modo de un territorio individualizado dentro de un colectivo. Por un lado coincidimos en los controles del cuerpo por ejemplo sobre el aborto, la sexualidad, el cuerpo como fuente de pecado; y por el otro lado, también puede referenciarse a la experiencia corporal como el tránsito necesario. El cuerpo permite la conexión con lo espiritual, la experiencia individualizada con lo divino, es decir, el cuerpo puede ser fuente de virtud y objeto sacralizado. En definitiva si el habitus es una estructura, lo es en tanto incorporada, o sea hecha cuerpo. De ahí que esa estructura sea un sistema de disposiciones que producen prácticas que hacen que lo social sea, y tenga, sentido para el agente. Las transformaciones territoriales en sentido amplio, y las mutaciones de las prácticas religiosas llevan consigo nuevas prácticas y cartografías, nuevas metáforas y símbolos, en la que se hacen carne y cuerpo.

\section{El cuerpo, territorio sagrado}

En esta parte del artículo se avanza sobre dos frentes en apariencia desconectados o como mundos paralelos, aunque como sabemos esto no es rígido en términos de hibridación cultural y búsquedas religiosas. Ejemplos nos sobran: las new age, el resurgimiento de religiosidades indígenas, las afrobrasileñas como el umbanda, las orientales en todas sus expresiones, recalan, se reinventan y se hacen cada vez más fuertes en las comunidades urbanas, en especial en la clase media. Los sectores populares no quedan por afuera de estas hibridaciones religiosas y culturales, muy por el contrario, aparecen expresiones de santería, re elaboraciones corporales y rituales católicos o protestantes que profesan individualmente o en comunidad, la búsqueda del bienestar material y espiritual. En estas formas sociales de religiosidad el cuerpo ocupa el centro del escenario.

En la visión del mundo moderno, se hizo hincapié en algunas miradas críticas de la globalización y su resonancia en la visualización del cuerpo, como mínima expresión territorial de reconstrucción de identidad. En la otra línea, se retoman los aportes que dan luz a categorías repensadas desde las cosmogonías indígenas mesoamericanas, por ejemplo el cuerpo como territorio sagrado, en un sentido complejo en que se da corporalidad a la naturaleza como un todo interconectado con la vida misma y, por ende, con las creencias religiosas.

Son varias las concurrencias de la época que posibilitan situar al cuerpo como epicentro de la reflexión sociocultural y que podrían sintetizarse en la transición de la modernidad hacia tiempos y espacios líquidos, parafraseando a Bauman. Esto es posible gracias al diálogo interdisciplinar y la complejidad de ideas que otorgan al cuerpo un significado como lente para observar a la dinámica social contemporánea u otras realidades hasta ahora invisibles, marginales o naturalizadas. Este proceso ha sido identificado con varias etiquetas: 
posmodernidad, segunda modernidad, nueva modernidad, entre otros. Proceso que puede sintetizarse como un sismo ideológico que experimentaron los sustratos paradigmáticos que sostuvieron la organización de los discursos de la ciencia y la cultura, de la vida cotidiana y con ello, las referidas al cuerpo y el territorio. Así el terreno sólido e inamovible de la ciencia expresa un desdibujamiento de las claridades de otrora. Plantea preguntas sobre lo ya sabido, preguntas sobre la emergencia social de otras formas de conocer, genera sombras y luces a partir del dato cualitativo y duda sobre lo cuantitativo, relativiza datos estadísticos, reconoce sujetos, métodos, complejidad. Es, en este escenario, donde el cuerpo es descolocado y pierde su anclaje en la naturaleza y en la biología, y puede filtrarse como una reconstrucción de sentidos y matrices culturales. De esta manera el cuerpo fragmentado, medido y objetivado por la modernidad positiva adquiere en el presente una dimensión integral que lo inscribe en los contextos y con los trazos de la cultura que lo atañe. En esta línea, la globalización es portadora de transformaciones en los modos de vida y acarrean cambios profundos en las culturas locales. Giddens (2000) ya nos plantea que es un error pensar que la globalización sólo concierne a los grandes sistemas, como el orden financiero mundial. La globalización no tiene que ver sólo con lo que hay "ahí afuera", remoto y alejado del individuo. Es también un fenómeno de "aquí dentro", que influye en los aspectos íntimos y personales de nuestras vidas.

La dispersión de las creencias en esta modernidad contemporánea es un hecho social sin precedentes, denominados como "nuevos movimientos religiosos". Estos abarcan un campo difuso de prácticas de cultos, sectas, grupos que llegaron recientemente para competir con las llamadas "religiones históricas". Se practica cada vez más un autoservicio cultural, un menú a la carta de experiencias religiosas que den bienestar espiritual y material. Estas prácticas, por lo general, prescinden de la mediación tradicional, institucional, de las iglesias. También, estas expresiones religiosas, plantean nuevas formas de sacralidad. Estas formas de creencias conllevan sistemas de significados que desplazan a circunscribir a la religión como modo de creer. "Para captar ese proceso como un movimiento de reestructuración global de lo religioso, que engloba a las propias religiones históricas, las transforma y las modifica, no es importante llevar el análisis, sobre todo, hacia el cambio de los contenidos de creencia, sino a la mutación de las estructuras del creer que esos cambios de contenido en parte revelan" (HERVIEU-LÉGER, 2008, p. 35), en términos espaciales podríamos parafrasear cuales son las estructuras corporales y del territorio en estas transformaciones sociales de los religioso. La modernidad contemporánea, en crisis o no, trae aparejado consigo la diversidad de expresiones religiosas y nuevas formas territoriales. "En el universo 'fluido', móvil, del creer, todos los símbolos son, en consecuencia, intercambiables, combinables, traspasables unos en otros. Todos los sincretismos son posibles, todos los reempleos son imaginables. (...) el 'creer religioso' no remite ni a objetos de creencia particulares, ni a prácticas sociales específicas, ni tampoco a representaciones 
originales del mundo, sino que puede ser definido de manera útil como un modo particular de organización y de funcionamiento del creer. El campo retenido aquí es el del tipo de legitimación aportado por el acto de creer." (2008, p. 37) El sentido de redefinición de lo religioso o la religión que brinda Hervieu-Léger nos permite dar otro paso hacia nuestro objeto del debate. En tiempos actuales, lo que legitima la práctica religiosa es el acto de creer y no las instituciones, a veces en la escala del individuo, a veces, a nivel colectivo. En esta dimensión, la corporalidad adquiere relevancia a la hora de interpretar las prácticas y creencias religiosas que toman como símbolo y objeto al cuerpo, es decir como una escala territorial apropiada.

La globalización, territorialización y desterritorialización, son procesos que conllevan la movilidad territorial de la población, y con ello sus culturas, creencias y religiones. Las búsquedas de identidad y la reconstrucción de una memoria utilitaria para una comunidad aparecen en la escena urbana o rural a miles de kilómetros. Se enfatizan algunas costumbres y la religión adquiere ese valor aglutinante de lo social. A tal punto se dan estos procesos, que las vestimentas, la apariencia corporal se resignifican como marcadores territoriales, y el cuerpo entonces aparecen como continuidades territoriales.

El cuerpo toma un lugar protagónico frente a la construcción de identidad desde la memoria colectiva de los grupos sociales y/o de movimientos religiosos. La construcción de una memoria que fije materialidad de y en las creencias del pasado resulta indispensable como reconstrucción de la identidad y pertenecía religiosa del presente, a la vez, que proyecta al grupo hacia el futuro cierto y definido. Estos componentes constituyen a los grupos en búsqueda de su identidad religiosa. A través del diseño y narrativa de una memoria, la comunidad fija rasgos de las representaciones de sí misma frente a la sociedad. Así las modalidades de construcción del relato mnemónico se enmarcan en un guión a partir de lo que cuenta para ellas en el presente. Este proceso genera representaciones compartidas y sostenidas por los miembros a esa comunidad religiosa, situada conceptualmente en un espacio intermedio entre la memoria individual y la memoria colectiva. En esos intersticios sociales se generan espacios sociales. Así es posible analizar el cuerpo y su imagen en tanto vehículo de disciplinamiento social-religioso, pero a la vez como locus donde es posible reinventar las identidades. En este sentido, el cuerpo ha tenido un rol central en los rituales, sacrificios y ofrendas a lo largo de la humanidad, variando según la religión o creencias del grupo social. En la actualidad la desregulación del campo religioso y las nuevas búsquedas espirituales posmodernas nos permitirían afirmar reinvenciones de prácticas territoriales donde el cuerpo permite diseñar trayectorias sociales más complejas, a la vez, ofrecer espacios de individualización con lo divino o sagrado desde la experiencia directa.

Ahora bien, en nuestro segundo eje no podemos de dejar de lado a la producción de la antropología latinoamericana que desde hace varias décadas pone el acento en el territorio como cuerpo humanizado a partir de estudios 
etnográficos de los pueblos originarios, por ejemplo en Colombia (PINZÓN, 2001; ECHEVERRI, 2004) o en México (BARABAS, 2010; MORALES DAMIÁN, 2010). Los pueblos recrean su historia, encuentran mecanismos rituales de transacción, buscan nuevas ubicaciones dentro de los nuevos sistemas de fuerzas que se conforman, proponen una redefinición de su situación de acuerdo con las móviles condiciones exteriores para lograr una mayor posición negociadora hacia el afuera. Es decir, presentan facetas hacia la exterioridad. Y el cuerpo adquiere el centro de las miradas. La geografía desde hace décadas se ha preocupado de las formas en que las personas se representan en el espacio y al espacio. Gottmann (1973) plantea así un aporte importante dado que el territorio a pesar de ser una entidad muy importante desde su concepción tradicional como la material, medible y concreta, también es el producto y expresión de las características psicológicas de los grupos humanos. Es más, podríamos completar estas ideas tomando distancia de estos autores, que el territorio se convierte en cuerpo o el cuerpo se puede expresar como una forma territorial como es en algunas cosmovisiones, sea la maya o la inca, por nombrar las más estudiadas por los antropólogos y arqueólogos.

Estos estudiosos no olvidan que antes que nada las religiones de los grupos indígenas del continente son territoriales ya que ideas y prácticas están estrechamente entrelazados como un tejido entre naturaleza, cuerpo, deidades y cultura. Por ello, cuando en el espacio se inscriben a través del tiempo usos, costumbres, memoria, rituales y formas diversas de organización social, se va constituyendo el territorio, y no de otra forma. La naturaleza no es solo montañas, valles y ríos sino deidades. Éstas no están por fuera de la vida de la comunidad sino que forman parte del sistema y de allí su corporalidad. Los lugares poseen hierofanías, y así es la montaña sagrada, o el bosque es sagrado o el árbol sagrado.

Los mayas, por ejemplo, plantean al cuerpo humano como parte integral del entorno geográfico e incluso es considerado una reproducción a escala del cosmos. "El territorio habitado es un todo coherente dentro del cual hombre, animales, plantas, astros, orientación geográfica y decurso temporal desempeñan una función específica y en la que todos son interdependientes, la naturaleza posee un orden cuyo centro es el ser humano. Asimismo, la íntima relación del hombre con su medio se asume como un deber religioso, se considera que todos los elementos que componen al mundo están 'vivos', es decir, dotados de un 'corazón', poseen una esencia divina. La población humana coexiste con la población vegetal, animal, mineral y meteórica en un intercambio biológico que se expresa en mitos y rituales específicos. Para el pensamiento maya, cuerpo y naturaleza son un solo territorio, el territorio de lo sagrado" (MORALES DAMIÁN, 2010, p. 279).

Estos aportes aparecen analizados, en este segundo momento, en varias líneas de narraciones de creencias actuales, aunque se resignifican para la trama social de los grupos de pertenencia. Este derrotero de ideas ha tenido la finalidad de poner en discusión las influencias que ejercen las tramas 
sociales y las experiencias religiosas, a modo de trayectorias, en la que el cuerpo accede al podio de las vinculaciones con el otro y con lo divino desde prácticas diversas.

\section{La religión como demarcador territorial y el cuerpo como territorio-sujeto}

A esta altura de las ideas desarrolladas, lo que importa es apreciar de qué manera tendencias por fuera del campo religioso del contexto histórico y social más generales afectan las formas de prácticas religiosas, y cómo las adaptaciones internas se re elaboran manteniendo su singularidad.

Los grupos religiosos se articulan en una gramática general que organiza la sociedad como tal, dinámica política y económica de la época. Por un lado, las iglesias, independientemente de los contenidos espirituales, actúan como una organización social y se constituyen en corporaciones. Pero por otro lado, existe un mosaico social totalmente dinámico que responde a las lógicas de la globalización y fragmentación cultural. Es decir, las tendencias de la religiosidad contemporánea responden a un nuevo orden territorial de la sociedad. Los procesos de territorialidad son los que configuran hoy nuestra política, economía y cultura del espacio. "Si el territorio es espacio marcado con los emblemas identificadores de su ocupación por un grupo particular, que a su vez inscribe, con sus características, la identidad de ese grupo que lo considera propio y lo transita libremente. En el mundo de hoy sería posible decir que hay un nuevo proceso en curso en lo que respecta a la territorialidad, entendida como experiencia particular, histórica y culturalmente definida en el territorio" (Segato, 2008:44). Si bien Sack (1986) ya nos proponía esta visión del territorio más flexible a partir de concepto de territorialidad, Segato lo re actualiza y hace referencia a procesos contemporáneos y los ajusta de tal manera que hace comprensible los procesos de transformaciones religiosas en nuestras sociedades. Esta flexibilidad territorial, como veremos, se exacerba aún más en contextos de translocalización de las culturas desenraizadas de sus símbolos y prácticas territoriales. Las maneras de localizar las identidades religiosas no pueden contar con el territorio demarcado que le dio origen a su cultura, necesariamente se encuentra menos ligado a esa materialidad y paisaje conocido. Esos territorios lejanos se reformulan en nuevos cuerpos.

El título de este parte del artículo expresa la principal síntesis. Por un lado es claro que los grupos religiosos trabajan centralmente en su difusión y expansión territorial en el sentido de comunidad. Los grupos religiosos intentan imprimir en los lugares que habitan marcas simbólicas de pertenencia: un templo, un tipo de organización social del espacio, la distribución de los objetos, los ritmos sociales y rituales que se materializan en territorios permanentes o efímeros. El proceso de territorialización es el ejercicio concreto de la gestión y administración de los bienes de salvación y de la doctrina imperante. Aunque el territorio hoy pasa a desprenderse de sus anclajes políticos del Estado, materiales y fijos, por el contrario adquieren movilidad, aunque 
coexisten. Por ese motivo, la identidad no es generada porque se comparte un territorio común sino que es la identidad la que concreta al territorio. En el tema urbano esto es bien visible cuando atravesamos la ciudad y nos encontramos con diversas realidades que hacen a la impronta de su cultura y religión.

La cultura del mundo contemporáneo se caracteriza por la movilidad territorial de la población que conlleva que las religiones o religiosidades modifiquen sus formas de adaptación, inserción y prácticas sociales. Resulta inevitable que se trasmuten las raíces territoriales y sean más flexibles, revalorando la unidad corporal como el locus privilegiado de la experiencia religiosa.

En otra escala, o mejor dicho en el interjuego de escalas de análisis, Segato (2008, p. 46) reflexiona justamente sobre los procesos de localización y demarcación territorial en los contextos globales y contemporáneos. "No se trata de un proceso de desterritorialización, ni siquiera de una nueva relación con el territorio, sino de una nueva producción del territorio" Es en este sentido un claro aporte para no caer en definiciones y redefiniciones conceptuales del territorio, cuando comenzamos a presentarlo como producción social, así el territorio es lo que es en ese contexto de producción.

En síntesis estamos presenciando procesos cada vez más profundos de una cultura territorial modificada. Ésta trae consigo matrices conocidas de territorialidades presentes o pasadas, producidas socialmente, demarcadas. Lo que antes era marginal e impensado en la relación identidad- territorio hoy es aceptado como que la población marca y diseña con su cultura a su territorio. Por otra parte, desarrolla una iconografía simbólica en el paisaje cultural que hoy resulta legitimado. Es el paisaje cultural, los geosímbolos religiosos y las prácticas los que construyen el territorio. De allí que los íconos visibles en el cuerpo que los sujetos portan constituyen paisajes, territorios habitados en una microescala de análisis espacial. El cuerpo se define como un territorio singular, un territorio transmutado. Estos cambios sin duda se producen en interacción con la exterioridad o marcos globales en que las sociedades y los sujetos se insertan $y$ trasmutan. El cuerpo- símbolo se reinventa en los diversos contextos culturales, ya sean de mercado, civilizaciones diferentes, según tiempo y espacio. "La diferencia entre un bien simbólico y un bien no simbólico está en la propia naturaleza de su significado. La naturaleza del bien simbólico refleja dos realidades: la mercancía y el significado, es decir, el valor mercantil y el valor cultural del bien" (ROSENDHAL, 2011, p. 237) Esta propuesta de Rosendahl plantea la relación entre el valor cultural y el valor mercantil de los símbolos en general, pero en la que el cuerpo no está fuera de la discusión. Otro aspecto, es que en la realidad social estas acepciones valor mercado y significado, van de la mano y no por separado.

El viraje de la dimensión religiosa del espacio entre el territorio- sujeto y el cuerpoterritorio radica justamente en las valorizaciones culturales en que juegan entre una frontera difusa y cada vez más compleja de las sociedades contemporáneas. Estas valorizaciones coexisten según los grupos y los credos, se entrelazan en un 
tejido social flexible, dinámico e incierto. Ya no solo nos podemos detener en los territorios administrados por grupos religiosos o iglesias, sino que el mundo conocido se expande en los territorios como experiencia, territorios como trayectorias de vida. Y aún más, territorios en donde se alcanzan a definir desde la corporalidad. Las elecciones de los sujetos sobre sus credos y prácticas no solo se enmarcan en contextos de privatización sino también desde lo público y lo colectivo. Aunque cuando nos referimos a privatización de lo religioso no debería circunscribirse a la interpretación de los privado e individual sino entenderlo, en un sentido de mercado, donde las ofertas de bienes de salvación y bienestar espiritual se pueden encontrar en el campo de lo privado y no institucional. "La relocalización de lo global se refiere a que el contexto de la globalización, elementos simbólicos circulan 'libremente' por circuitos mercantiles y tecnologías de la comunicación, a la vez que los buscadores espirituales constantemente encuentran asidero y legitimación de sus menús creyentes mediante procesos de relocalización y reanclaje en las religiones tradicionales o populares capaces de proporcionar linaje y memoria, símbolos de arraigo emotivo y pertenencia territorial. Estos actores cosmopolitas buscan continuidad en la discontinuidad. $Y$ en esa búsqueda de situar lo inestable donde el cuerpo recupera un sentido estratégico para el reanclaje de las culturas e identidades de la posmodernidad" (DE LA TORRE, 2008, p. 50) La claridad de esta autora deja poco margen para la re elaboración heurística de sus ideas, por el contrario nos propone una síntesis final para la articulación de nuestras ideas iniciales: establecer nexos entre territorio, cuerpo y religión.

\section{Conclusiones provisórias}

Resulta difícil proponer conclusiones dado que este artículo invita al debate más que proponer verdades concluyentes. Lo que se intentará es rescatar algunas ideas centrales que pueden ser retomadas o refutadas en próximos trabajos, entre ellas:

En principio el cuerpo otorga nuevos significados sociales a la práctica religiosa y resulta en una lente potente para observar la dinámica social contemporánea u otras realidades hasta ahora invisibles.

La expresión de lo religioso se simboliza en el cuerpo pero en una trama cultural cambiante y diversa.

La corporalidad o los gestos corporales no resultan de la acción de la razón sino más bien como la acción de la sociedad sobre el cuerpo.

El territorio se convierte en cuerpo o el cuerpo se puede expresar como una forma territorial como es en algunas cosmovisiones, e inclusive pueden ser reinventadas en términos de los impactos culturales de la globalización.

Estos procesos espaciales de la religiosidad ya no se explican tan solo haciendo énfasis en los procesos de desterritorialización, ni siquiera de una nueva relación con el territorio, sino a partir de una nueva producción del territorio.

Finalmente, porqué el cuerpo se reconvierte en el locus privilegiado entre los 
divino y lo pagano en nuestras sociedades. El cuerpo desplazará todo tipo de mediación religiosa, qué mapas de creencias construyen. Estos cuerpos son resultantes inevitables de un arreglo espacial (tal como lo plantea D. Harvey) como la otra cara del (des) orden mundial que dialoga con formas socio territoriales mutadas y fragmentadas. Qué paisajes y territorios podremos imaginar cómo marcadores de identidades religiosas. Son interrogantes que nos provocan seguir pensando en la espacialidad religiosa de nuestra realidad latinoamericana.

\section{BibLIOGRAFíA}

BARABÁS, Alicia. El pensamiento sobre el territorio en las culturas indígenas de México. Avá. Revista de Antropología, Universidad Nacional de Misiones, Posadas, n. 17, junio 2010

BENEDETTI, Alejandro. Territorio: concepto integrador de la geografía contemporánea. In: SOUTO, Patricia (coord.) Territorio, Lugar, Paisaje. Prácticas y conceptos básicos en geografía. Buenos Aires: Colección Libros de Cátedra, Facultad de Filosofía y Letras, UBA, pp. 11-82, 2011.

BOURDIEU, Pierre. Cosas dichas. Buenos Aires: Gedisa, 1988.

CARBALLO, Cristina, (compiladora). Diversidad cultural, creencias y espacio. Referencias empíricas. Luján: PROEG - Departamento de Ciencias Sociales, Universidad Nacional de Luján, 2007.

(Dir.). Cultura, territorios y prácticas religiosas. Buenos Aires: Ediciones Prometeo, 2009.

CHIOZZA, Elena y CARBALlO, Cristina. Introducción a la Geografía. Buenos Aires: Prometeo-Universidad Nacional de Quilmes Editorial, 2009. Reimpresión.

DE LA CALLE VALVERDE, J. El gesto analógico. Una revisión de las técnicas del cuerpo de Marcel Mauss. Revista Latinoamericana de Estudios sobre Cuerpos, Emociones y Sociedad-RELACES. N ${ }^{\circ} 7$. Córdoba, año 3, n. diciembre-marzo, 2011. Disponible en: http://www.relaces.com.ar/fullissue/RELACES-N7.pdf

DE LA TORRE, René. La imagen, el cuerpo y las mercancías en los procesos de translocalización religiosa en la era global. Ciências Sociais e Religão, Porto Alegre, ano 10, n. 10, p. 49-72, 2008
ECHEVERRI, Juan A. Territorio como cuerpo y territorio como naturaleza: ¿Diálogo intercultural? In: SURRALLES, A y GARCÍA HIERRO, P (eds.) Tierra adentro: Territorio indígena y percepción del entorno. Copenhague: IWGIA, 2004.

GIDDENS, Anthony. Un mundo desbocado. Los efectos de la globalización en nuestras vidas. Madrid: Taurus, 2000.

GIMENEZ, Gilberto. Cultura, territorio y migraciones. Aproximaciones teóricas. Alteridades, México D.F., n. 22, p. 5-14, 2001.

GOTTMANN, Jean. The significance of territoty. Charlottes-ville: The University Press of Virginia, 1973

HERVIEU-LÉGER, Danièle. Producciones religiosas de la modernidad. In: MALLIMACI, Fortunato (Comp.) Modernidad, Religión y Memoria, Buenos Aires: Ediciones Colihue, p. 15-39, 2008

LE BRETON, David. La sociología del cuerpo. Buenos Aires: Nueva Visión, 2002. [1992]

LOBATO CORRÊA, Roberto. Espaço: um coneito-chave d Geografía. In: ELIAS DE CASTRO, I; DA GOMES, P. y LOBATO CORRÊA, R. (Orgs.) Geografía conceitos e temas. Rio de Janeiro: Bertrand, 1995.

PINZON, Carlos y GARAY, Gloria. El cuerpo como territorio sagrado, 2001. Disponibile en: http://cursoshistorico.iteso.mx/moodle/pluginfile.php/405992/mod_r esource/content/0/Pinzony_garay_cuerpo_y_chamanismo_en_colom bia.pdf

ROSENDAHL, Zeny. Religión, bienes simbólicos, mercado y red. In: ZUSMAN, Perla; HAESBAERT, Rogeiro; CASTRO, Hortencia y ADAMO, Susana (Eds.) Geografías culturales. Aproximaciones, intersecciones y desafíos. Buenos Aires: Editorial de la Facultad de Filosofía y Letras, UBA, p. 235-254, 2011

SACK, Robert. Human territoriality. Its theory and history. Cambridge: Cambridge University Press, 1986.

SEGATO, Rita. La faccionalización de la república y el paisaje religioso como índice de una nueva territorialidad. In: ALONSO, Aurelio (Comp.) América Latina y el Caribe. Territorios religiosos y desafíos para el diálogo. Buenos Aires: CLACSO, Consejo Latinoamericano de Ciencias Sociales, p. 41-81, 2008. Disponible en: http://bibliotecavirtual.clacso.org.ar/ar/libros/grupos/alonso/Segato.p $\underline{\mathrm{df}}$ 
Titulo

ESPAÇO E CULTURA, UERJ, RJ, N. 32, P.61-78, JUL./DEZ. DE 2012 http://www.e-publicacoes.uerj.br/index.php/espacoecultura/

E-ISSN 2317-4161 
RESUMO: HÁ UMA CONSIDERÁVEL REVISÃO TEÓRICA E EMPíRICA DA NOCÃ̃o DE TERRITÓRIO, CORPO E ESPACIALIDADE RELIGIOSA. A

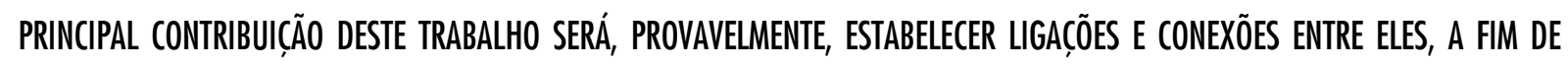
INTERPRETAR AS FORMAS CONTEMPORÂNEAS DE CORPORALIDADE EM SUAS DIVERSAS MANIFESTAC̄̃̃ES. OS CORPOS SÃo EXPRESSÕES COMO FORMAS DE CARTOGRAFIA RELIGIOSA. 0 TRABALHO ESTÁ ORGANIZADO DA SEGUINTE FORMA: A PRIMEIRA FASE LEVANTA ALGUMAS IDÉ|AS SOBRE CORPO E TERRITÓRIO A PARTIR DE SUA FUNÇ̃̃O SOCIAL E CULTURAL. A SEGUNDA LINHA É TOMAR O CORPO COMO TERRITÓRIO SAGRADO. AO MESMO TEMPO, APRESENTA PERSPECTIVAS QUE VÃo DESDE a GLOBALLZAÇÃO E SEUS EFEITOS SOBRE

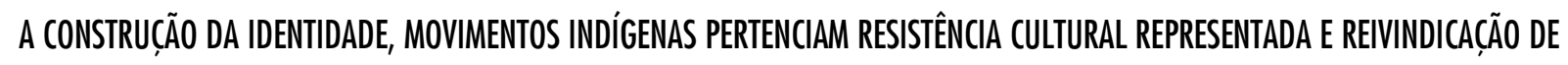
SEUS GANHOS SOCIAIS E ECONÔMICOS. A TERCEIRA E ÚLTIMA, TEM COMO OBJEIIVO REPENSAR O CORPO E TERRITÓRIO COMO EXPRESSÕES E APROPRIAC̄̃̃ES DA REALIDADE RELIGIOSA CONTEMPORÂNEA.

PALAVRAS- CHAVES: TERRITÓRIO, CORPO, RELIGIOSIDADE, CORPORALIDADE. 